\title{
Article
}

\section{Graphene and Carbon Nanotubes Fibrous Composite Decorated with PdMg Alloy Nanoparticles with Enhanced Absorption-Desorption Kinetics for Hydrogen Storage Application}

\author{
Bassim Arkook 1,2**(D), Ahmed Alshahrie 1,3, Numan Salah ${ }^{3} \mathbb{D}$, Mohammad Aslam 4 (D), Saeed Aissan ${ }^{1}$, \\ Ashwaq Al-Ojeery ${ }^{1,5}$, Ahmed Al-Ghamdi ${ }^{1}$ (D), Akihisa Inoue ${ }^{1,6}$ and El-Sayed Shalaan ${ }^{1, *(D)}$
}

check for updates

Citation: Arkook, B.; Alshahrie, A.; Salah, N.; Aslam, M.; Aissan, S.; Al-Ojeery, A.; Al-Ghamdi, A.; Inoue, A.; Shalaan, E.-S. Graphene and Carbon Nanotubes Fibrous Composite Decorated with PdMg Alloy Nanoparticles with Enhanced Absorption-Desorption Kinetics for Hydrogen Storage Application. Nanomaterials 2021, 11, 2957. https:// doi.org/10.3390/nano11112957

Academic Editor:

Diego Cazorla-Amorós

Received: 15 October 2021

Accepted: 2 November 2021

Published: 4 November 2021

Publisher's Note: MDPI stays neutral with regard to jurisdictional claims in published maps and institutional affiliations.

Copyright: (c) 2021 by the authors. Licensee MDPI, Basel, Switzerland. This article is an open access article distributed under the terms and conditions of the Creative Commons Attribution (CC BY) license (https:/ / creativecommons.org/licenses/by/ $4.0 /)$.
1 Department of Physics, Faculty of Science, King Abdulaziz University, Jeddah 21589, Saudi Arabia; aalshahri@kau.edu.sa (A.A.); saealzahrani@kau.edu.sa (S.A.); aaalaegiry@uj.edu.sa (A.A.-O.); agamdi@kau.edu.sa (A.A.-G.); ainouebmg@yahoo.co.jp (A.I.)

2 Department of Physics and Astronomy, University of California, Riverside, CA 92521, USA

3 Center of Nanotechnology, King Abdulaziz University, Jeddah 21589, Saudi Arabia; nsalah@kau.edu.sa

4 Center of Excellence in Environmental Studies, King Abdulaziz University, Jeddah 21589, Saudi Arabia; aslam312@gmail.com

5 Department of Physics, Faculty of Science, Jeddah University, Jeddah 23890, Saudi Arabia

6 International Institute of Green Materials, Josai International University, Togane 283-8555, Japan

* Correspondence: barkook@kau.edu.sa (B.A.); eshalan@kau.edu.sa (E.-S.S.)

Abstract: We describe a graphene and fibrous multiwall carbon nanotubes ( $f$-MWCNT) composite film prepared by plasma-enhanced chemical vapor deposition for use as a suitable and possible candidate of hydrogen storage materials. A high storage capacity of $5.53 \mathrm{wt} \%$ has been obtained with improved kinetics. The addition of binary PdMg alloy nanoparticles to the surface of graphene-fibrous nanotubes composite films raised the storage capacity by $53 \%$ compared to the film without PdMg decorated nanoparticles. Additionally, the graphene/ $f$-MWCNT composite film decorated with PdMg nanoparticles exhibited an enhanced hydrogen absorption-desorption kinetics. The fibrous structure of the MWCNTs, alongside graphene sheets within the film, creates an enormous active region site for hydrogen reaction. The addition of $\mathrm{PdMg}$ nanoparticles enhanced the reaction kinetics due to the catalytic nature of Pd, and increased the hydrogen content due to the high absorption capacity of $\mathrm{Mg}$ nanoparticles. The combination of $\mathrm{Pd}$ and $\mathrm{Mg}$ in a binary alloy nanoparticle enhanced the hydrogen capacity and absorption-desorption kinetics.

Keywords: hydrogen storage; carbon nanotubes; nanomaterials; thin films

\section{Introduction}

Today, hydrogen is considered the next-generation energy carrier for vehicles and fixed engines or power sources [1-5]. Hydrogen exhibits the highest energy density per mass of around $40 \mathrm{kWhkg}^{-1}$. When used as a source of energy, the exhaust product is water only. Before hydrogen can be used in portable applications, it is necessary to find the appropriate technology that is most economical and safe to store hydrogen at the highest possible density. In practice, for a light-duty vehicle, the key for hydrogen storage is how to release the amount of hydrogen that has been stored to allow a driving range of at least $480 \mathrm{~km}$ against the vehicle engineering limits of weight, volume, safety, efficiency, and cost-plus, of course, the durability. There are currently some different hydrogen storage technologies that are heavily investigated [6-13]. Unfortunately, all those technologies did not reach the satisfaction conditions for being commercialized. Accordingly, there is a strong demand for innovative technology or new materials that exhibit distinctive and unique properties for hydrogen storage. 
In general, hydrogen can be stored in gaseous or liquid form. However, these methods require a significantly large volume and weight, which makes them unsuitable for portable applications. Therefore, storing hydrogen in solid form is a necessary solution, for example, in the transportation sector.

Solid-state hydrogen storage materials can be classified into: $\mathrm{i}$-hydrides (light metal hydrides and complex metal hydrides) [14-17]; ii-carbon-based [18-25]; iii-chemical hydrogen storage [26-33]; and iv-new advanced materials [34-41]. Among these materials, the hydride is preferred for hydrogen storage due to two facts: large amounts of hydrogen can be stored, and hydrogen absorption and desorption kinetics can be improved by varying the metallic alloy elements or compositions.

On this subject, $\mathrm{MgH}_{2}$ has been one of the most considered materials among several high-potential hydride systems due to its high volumetric $\left(110 \mathrm{~kg} / \mathrm{m}^{3}\right)$ and gravimetric (7.6 wt\%) hydrogen storage capacities, as well as its natural abundance and good reversibility. However, the slow hydrogenation kinetics, low hydrogen diffusion coefficient, and surface oxide layer formation limit practical applications. Therefore, several solutions have been proposed to enhance and improve the hydrogen storage properties, including alloying $\mathrm{Mg}$ with other elements and catalysts or producing it at the nanoscale [42-44].

Accordingly, various transition metals, rare earth metals, and other elements produce magnesium-based metal alloy hydrides for hydrogen storage. In addition, some noble metal catalysts, such as $\mathrm{Pd}$, have been reported to be effective in assisting the hydrogenation of $\mathrm{MgH}_{2}$. It was found that during the hydrogenation process, the Pd metal catalyst has a significant effect, causing an increase in the diffusion of hydrogen atoms at the $\mathrm{Pd}-\mathrm{Mg}$ interface. Many investigations are needed to inspect the properties of the lightweight metal hydrides and tailor their absorption/desorption kinetics.

Another type of metal hydride is complex hydride [16,45-48]. Today, the highest gravimetric hydrogen density is about $13.8 \mathrm{wt} \%$ for $\mathrm{LiBH}_{4}$, making this complex the ideal hydrogen storage material for vehicle transportations if the storage kinetics are improved (Figure 1) [49]. Therefore, complex hydrides fortified more studies in the field of hydrogen storage materials. Today, there is a need for discovering a new complex hydride based on lightweight metals with the highest possible gravimetric hydrogen density.

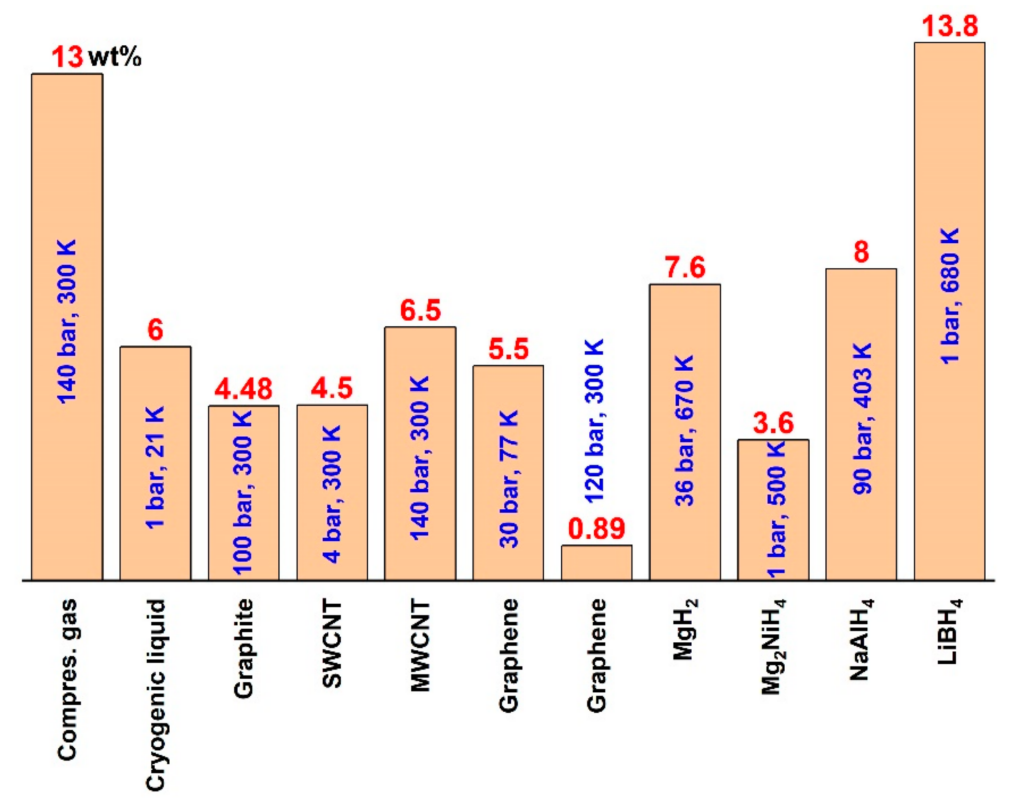

Figure 1. Hydrogen storage capacity (wt $\%$ ) for some important materials. The kinetic conditions for hydrogen storage are shown.

Dual-tuning impacts of the thermodynamics and kinetics for hydrogen storage materials are significant issues for the hydrogen economy, especially for the metal hydrides such 
as $\mathrm{LiBH}_{4}$ and $\mathrm{MgH}_{2}$. Newly developed ball milling with aerosol spraying for dual-tuning of the thermodynamics and kinetics of $\mathrm{LiBH}_{4}$ shows future opportunities to improve the reversible hydrogen storage properties of metal hydride-based materials in a solid state $[42,50-53]$.

Besides metal hydride-based hydrogen storage materials, many carbon-based nanostructured materials have been considered. Experiments showed that the adsorptiondesorption process is reversible, and the amount of adsorbed hydrogen is relatively low (about $3 \mathrm{wt} \%$ ) $[12,21,23,54]$. Carbon nanostructures and other nanoporous materials have also been examined for hydrogen storage $[23,25,55-58]$. It is found that the amount of absorbed hydrogen, which is very low, increased with temperature and pressure, indicating that the mechanism of storing is of a chemical reaction nature, preferably physisorption. It is concluded that the relatively low values of gravimetric and volumetric hydrogen densities for carbon, carbon-based structures, and other porous materials are significant drawbacks.

When selecting a potential storage system, the kinetic characteristics of the hydrogen storage material must be considered. Indeed, obtaining a rapid hydrogenationdehydrogenation process is a significant issue for many hydrogen storage materials. Therefore, the reversible hydrogen storage kinetics and capacity strongly depend on the materials' preparation methods and applied conditions.

Inspired by the above facts, we have investigated light metal hydrides combined with a carbon-based nanostructure to obtain an excellent hydrogen storage material to assist future clean energy.

\section{Materials and Methods}

Before deposition of carbon nanotubes, a metal-supported catalyst is required. Typically, nickel or titanium metal is employed to grow fine vertical tubes on a particular substrate. Silicon is the common universally utilized substrate for CNTs growth. This research study uses an alloy consisting of two different metals as a metallic catalyst, specifically palladium and magnesium. This alloy is supposed to generate long carbon nanotubes with fibrous-like structures. The fibrous carbon nanotubes will enhance hydrogen absorption-description kinetics. Moreover, $10 \mathrm{~nm}$ PdMg thin alloy film was deposited on Pt substrate by co-sputtering (Univex 360, Leybold Inc., Cologne, Germany). Two high purity (99.999\%) targets, $\mathrm{Pd}$ and $\mathrm{Mg}$, were concurrently sputtered to form the alloy layer with a power of 40 and 30 watts, respectively. The base pressure was $10^{-6}$ mbar, the working pressure was $10^{-2} \mathrm{mbar}$, and the argon partial pressure was $90 \mathrm{sccm}$. A plasma-enhanced chemical vapor deposition (PECVD) system (EasyTube 2000, FirstNano Inc., Central Islip, NY, USA) grew carbon nanotubes on Pt substrate loaded with the PdMg catalyst. After deposition of the PdMg alloy layer on Pt substrate was accomplished, the substrate was transferred to PECVD system. The PECVD system was supplied with a graphite heater, a three zones furnace to obtain a uniform temperature throughout the substrate, a vacuum pump, and a quartz tube. The quartz tube was evacuated to a base pressure of $10^{-3}$ mbar. As the first step, $\mathrm{N}_{2}$ is purged into the quartz tube for two minutes and followed by an Ar gas for $5 \mathrm{~min}$. Hydrogen gas with a flowing rate of $90 \mathrm{sccm}$ was introduced into the quartz tube, and the oven was heated to $500^{\circ} \mathrm{C}$ with a heating rate of $20^{\circ} \mathrm{C} / \mathrm{min}$. The system was halted at these conditions for $30 \mathrm{~min}$. After this time, the furnace was adjusted to reach 650 ${ }^{\circ} \mathrm{C}$ with a $5{ }^{\circ} \mathrm{C} / \mathrm{min}$ heating rate. At $650{ }^{\circ} \mathrm{C}, \mathrm{NH}_{3}(90 \mathrm{sccm})$ was injected into the quartz tube for plasma initialization $(50 \mathrm{~W})$. After plasma stabilization at $60 \mathrm{~W}$, a high purity $\mathrm{C}_{2} \mathrm{H}_{2}$ gas $(25 \mathrm{sccm})$ was injected into the quartz tube to grow the carbon nanotubes. The oven cooled down to room temperature under an Ar atmosphere when the preferred reaction time was achieved. The obtained carbon nanotubes were transferred to the sputtering chamber to deposit the PdMg thin alloy top layer with the conditions mentioned earlier.

The obtained nanocomposite samples were examined by using a field emission scanning electron microscope (ZEISS Sigma FESEM, Carl Zeiss GmbH, Oberkochen, Germany), XRD (Ultima IV, Rigaku Corporation, Tokyo, Japan), and a Raman spectroscope (HR800, HORIBA Europe GmbH, Oberursel, Germany). 
Electrochemical hydrogen storage was performed using a standard three-electrode cell connected to an electrochemical workstation (PGSTAT302N, Metrohm AG, Herisau, Switzerland). All measurements have been done at an ambient temperature and pressure. A commercial platinum sheet with a total surface area of about $1 \mathrm{~cm}^{2}$ was used as a counter electrode. The thin film sample was attached (free substrate surface) to a platinum wire using a conductive adhesive to prepare the working electrode. A chemically inert insulating varnish was applied to the contact and edges of the film to protect them from the electrolyte. The active surface area of the working electrode was about $2 \mathrm{~cm}^{2}$. The charged-discharged experiment was performed at a constant current of $\pm 150 \mathrm{~mA}$ under a cut-off potential of $-0.5 \mathrm{~V}$ vs. $\mathrm{Ag} / \mathrm{AgCl}$ electrode. To account for the high-rate discharge-ability (HRD), the working electrode was discharged at different constant currents $(\mathrm{A}=25,50,75,100$, and $125 \mathrm{~mA} / \mathrm{g}$ ). HDR is defined as HRD $=\mathrm{C}_{\mathrm{A}} / \mathrm{C}_{25} \times 100 \%$, and $\mathrm{C}_{\mathrm{A}}$ is the maximum capacity at the selected current density.

\section{Results}

Figure 2 shows the XRD pattern of graphene $/ f$-MWCNT composite film decorated with top PdMg alloy layer (G/f-MWCNT@PdMg). The XRD pattern in Figure $2 \mathrm{~b}$ displayed three diffraction peaks, two intense diffraction peaks around $36^{\circ}$ and $42^{\circ}$ and a low intensity diffraction peak around $31^{\circ}$. These peaks are assigned to (440), (533), and (422) diffraction plans of typical C60. Fullerenes and carbon nanotubes are allotropes of carbon categorized by a void structure and remarkable physical properties. The void sites are advantageous for hydrogen adsorption [54]. This result indicates that graphene and $f$-MWCNTs are well graphitized. There is no indication of any carbon impurities. The metal particles of the PdMg top thin layer are not recognized due to their nanoparticle size of the alloy. In fact, due to the surface nature of carbon nanotubes, the metal particles of $\mathrm{PdMg}$ alloy are dispersed and implanted into the composite structure instead of forming a continuous top thin layer. Metal nanoparticles, when distributed over carbon nanostructure materials, demonstrate improved storage capacities and enhanced adsorption-desorption kinetics $[59,60]$.

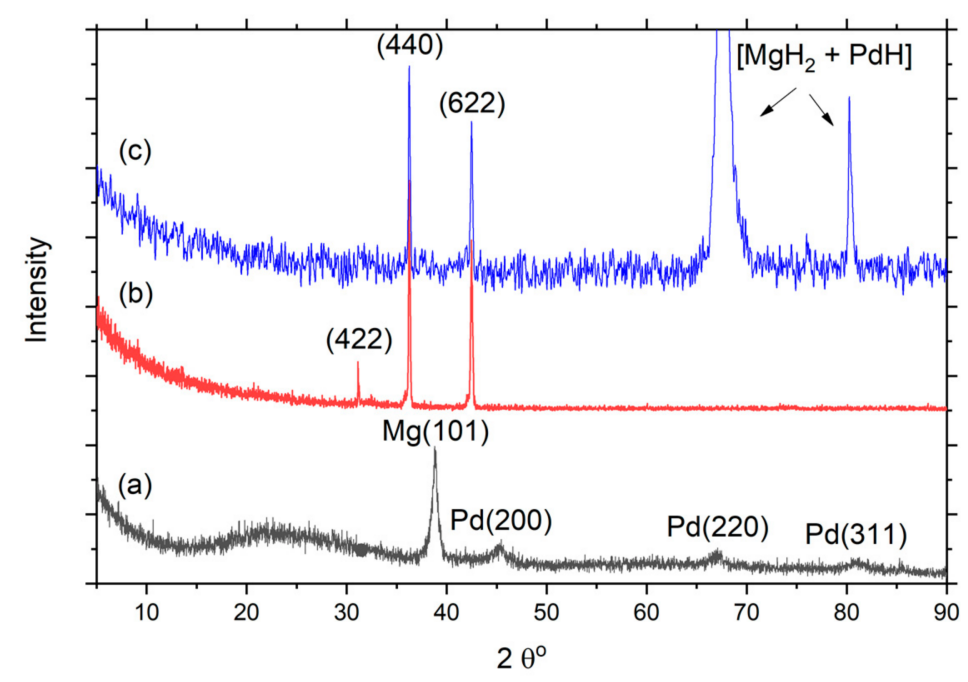

Figure 2. XRD pattern: (a) PdMg binary alloy deposited on a glass substrate, and (b,c) graphene/fMWCNT nanocomposite decorated with PdMg alloy nanoparticles deposited on Pt substrate before and after hydrogenation, respectively.

The bottom XRD pattern in Figure 2a is the typical for PdMg alloy deposited on glass substate. The pattern exhibits one intense peak around $38.81^{\circ}$ and three other small peaks around $45.32^{\circ}, 66.98^{\circ}$, and $80.96^{\circ}$. The first intense peak is corresponding to a hexagonal Mg structure (JCPDS card no. 00-350-821), while the other three smaller peaks are corresponding to an fcc Pd structure (JCPDS card no. 00-152-2945). 
It is noted that the position of the first peak is shifted toward a larger angle in comparison to bulk Mg, while the other three peaks shifted toward smaller angles. The calculated lattice parameter of Pd is $3.96 \AA$, which is larger than the corresponding bulk cubic structure $(\mathrm{a}=3.89 \AA)$. This information suggested that the cell volume of $\mathrm{Mg}$ is contracted due to the presence of $\mathrm{Pd}$ atoms, while the cell volume of $\mathrm{Pd}$ is enlarged due to the presence of $\mathrm{Mg}$ atoms. Hence, it is concluded that the deposited PdMg film contains two mixed phases: a host Mg phase with dopped $\mathrm{Pd}$ atoms, and a host Pd phase with dopped Mg atoms. More information is presented in Table 1.

Table 1. Structure parameters of PdMg alloy.

\begin{tabular}{|c|c|c|c|c|c|c|c|c|c|c|}
\hline \multirow{2}{*}{ Phase } & \multicolumn{2}{|c|}{$2 \theta^{\circ}$} & \multicolumn{2}{|c|}{ d Spacing, Å } & \multirow{2}{*}{$\Delta \theta^{\circ}$} & \multirow{2}{*}{$\Delta \mathrm{d}, \AA$} & \multicolumn{2}{|c|}{ Lattice Parameters, Å } & \multicolumn{2}{|c|}{ Cell Volume, Å3 } \\
\hline & Film & Bulk & Film & Bulk & & & Film & Bulk & Film & Bulk \\
\hline $\operatorname{Mg}(101)$ & 38.81 & 36.62 & 2.318 & 2.450 & 2.19 & -0.132 & - & - & & \\
\hline Pd (200) & 45.32 & 46.66 & 1.998 & 1.945 & -1.32 & 0.053 & 3.99 & 3.89 & 63.52 & 58.87 \\
\hline $\operatorname{Pd}(220)$ & 66.98 & 68.12 & 1.396 & 1.375 & -1.14 & 0.021 & 3.95 & & 61.63 & \\
\hline $\mathrm{Pd}(311)$ & 80.96 & 82.09 & 1.186 & 1.173 & -1.14 & 0.014 & 3.94 & & 61.16 & \\
\hline
\end{tabular}

$\mathrm{XRD}$ is not a very useful tool when distinguishing between graphene and carbon nanotube is required. Raman spectroscopy is a very effective tool in such a situation. Usually, Raman spectra for graphene or nanotubes include three different bands: G-band, $\mathrm{D}$-band, and 2D band. The G-band arises from the vibration of $\mathrm{sp} 2$ carbon atoms. The D-band is known as the disorder band and is related to structural defects of sp3 carbon. The band is strong in carbon nanotubes and typically very weak in graphene. The shape of the $2 \mathrm{D}$ band is very important. A single symmetric peak means one graphene layer, while more graphene layers produce an asymmetric 2D peak [61].

Figure 3 shows Raman spectra of the G/f-MWCNT@PdMg sample. The figure exhibits three bands located at $1355 \mathrm{~cm}^{-1}, 1587 \mathrm{~cm}^{-1}$, and $2688 \mathrm{~cm}^{-1}$ corresponding to D-, G-, and 2D-band, respectively. Using a 2D band, the difference among graphene, nanotubes, and graphene-carbon nanotube composite can be recognized. Nanotubes always display intense 2D bands, while graphene always shows very weak intensity. Here, the 2D band is seen with reasonable intensity, indicating that a mixed phase of graphene and carbon nanotubes is successfully formed.

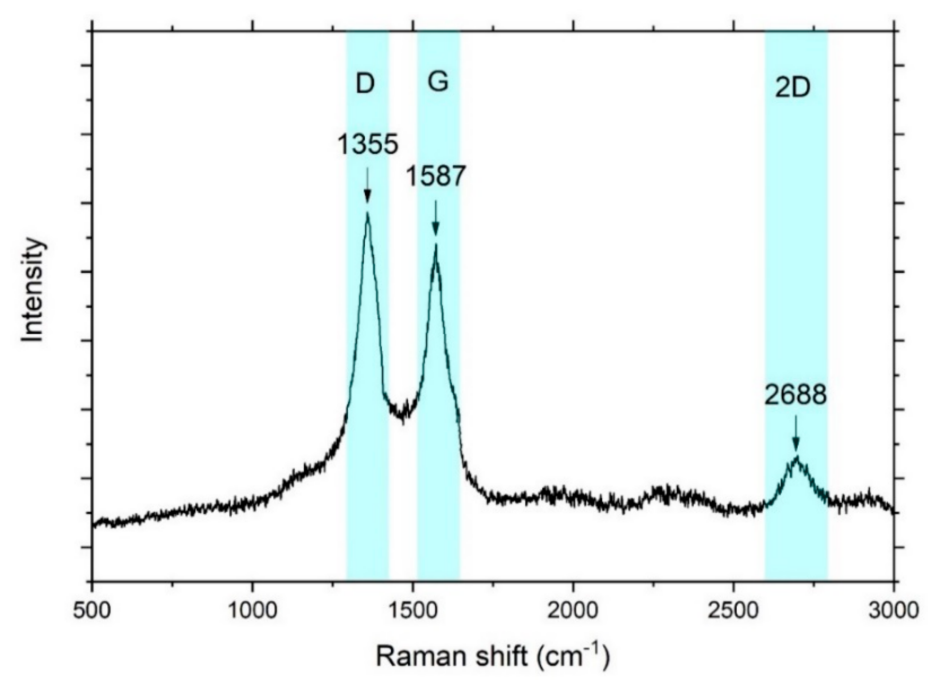

Figure 3. Raman spectra of graphene/f-MWCNT nanocomposite @PdMg sample.

The surface morphology of the prepared nanocomposite is presented in Figure 4. The prepared composite without PdMg alloy nanoparticles is shown in Figure $4 \mathrm{a}, \mathrm{c}$, while the composite decorated with PdMg nanoparticles is given in Figure $4 \mathrm{~b}, \mathrm{~d}$. The PdMg nanopar- 
ticles are dispersed into the bulk of the composite film as indicated in the figure by yellow shapes. All images display the fibrous structure of carbon nanotubes. There are some transparent layers of graphene shown in Figure $4 \mathrm{~d}$ by green shapes. These SEM images with the information deduced from Raman spectra confirm that the graphene/f-MWCNT nanocomposite @PdMg alloy nanoparticles are successfully formed. The composite contains many voids and hollow sites, which are favorable for high-capacity hydrogen absorption characteristics. The presence of PdMg nanoparticles is expected to increase storage capacity and enhance reaction kinetics.
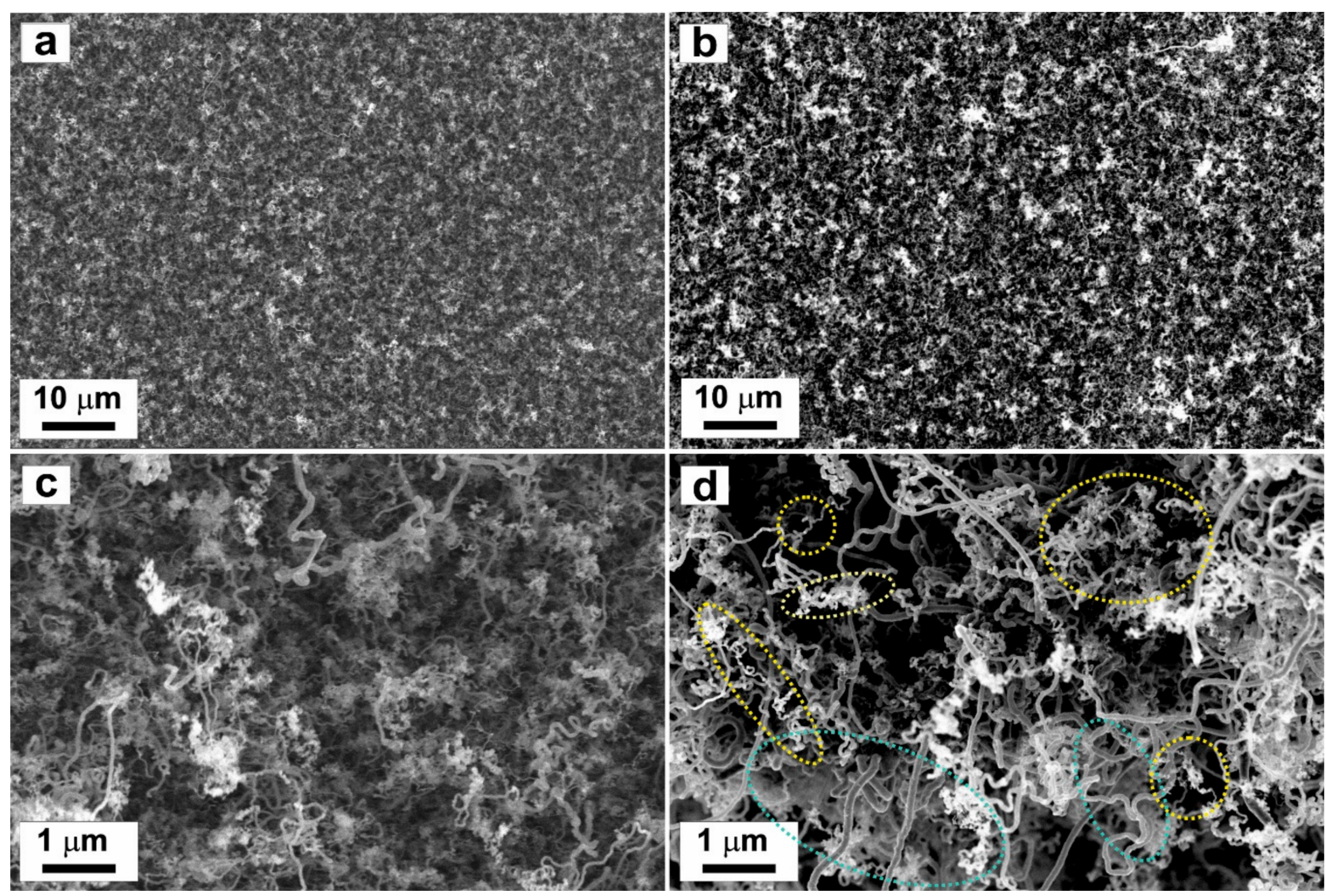

Figure 4. High-resolution SEM images of $(\mathbf{a}, \mathbf{c})$ graphene/f-MWCNT nanocomposite and (b,d) graphene/f-MWCNT nanocomposite decorated with PdMg alloy nanoparticles deposited on Pt substrate. Yellow ovals highlight the decorative clusters of PdMg nanoparticles.

The charge and discharge curves of G/f-MWCNT and G/f-MWCNT@PdMg nanocomposites are shown in Figure 5a,b, respectively. A discharge capacity of $765 \mathrm{mAh} / \mathrm{g}$ is obtained in the G/f-MWCNT electrode corresponding to $\sim 2.86 \mathrm{wt} \%$ hydrogen, while the best discharge capacity of G/f-MWCNT@PdMg electrode is $1478 \mathrm{mAh} / \mathrm{g}$ corresponding to $\sim 5.53 \mathrm{wt} \%$ hydrogen content. It has been stated that the aligned carbon nanotubes exhibit a better hydrogen absorption capacity compared to non-aligned nanotube [62]. Here, the G/f-MWCNT@PdMg sample shows a higher absorption capacity than the sample without PdMg nanoparticles. In fact, the obtained capacity for graphene/carbon nanotube composite decorated with PdMg nanoparticles displays a higher absorption capacity than other carbon nanotubes materials found in the literature considering the film structure of the sample $[12,20,21,23,24,36,62]$. After several cycles, the samples almost maintain their capacities (the figure is not shown here). 


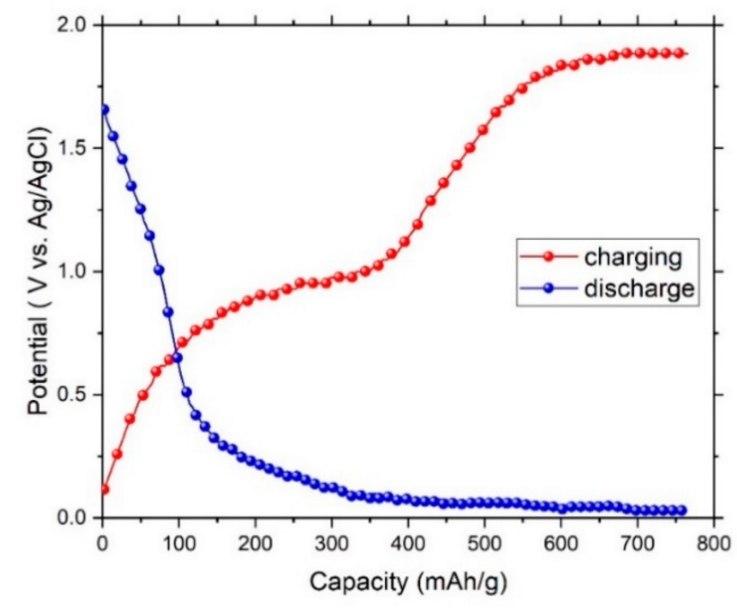

(a)

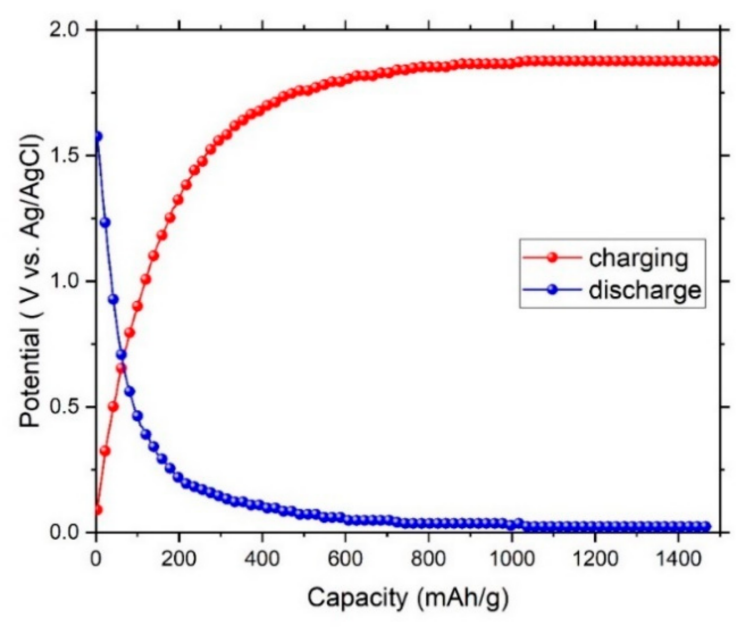

(b)

Figure 5. The charge-discharge curves in 3M KOH electrolyte for (a) G/f-MWCNT electrode; (b) G/f-MWCNT@PdMg electrode.

The discharge capacities with appropriate cyclic stabilities and the dehydrogenation activation properties are the key parameters to judge for good hydrogen storage materials. Due to the presence of many suitable absorption sites for hydrogen storage, the carbon nanotubes possessed a high theoretical storage capacity exceeding $2500 \mathrm{mAh} / \mathrm{g}$ depending on structure, morphology, and defect concentration; however, the maximum experimental storage capacities are still frustrating [63,64].

Figure 6a shows the discharge capacities (30 cycles) at a current density of $25 \mathrm{~mA} / \mathrm{g}$ for $\mathrm{G} / f$-MWCNT and G/f-MWCNT@PdMg nanocomposites. A noticeable enhancement of discharge capacity and cyclic stability is obtained for the G/f-MWCNT@PdMg sample in comparison to the $G / f$-MWCNT sample. Another important factor for a suitable candidate for storage materials is its ability to sustain the discharge performance at a high current density. The HRD for G/f-MWCNT and G/f-MWCNT@PdMg nanocomposites at different discharge current densities is shown in Figure $6 \mathrm{~b}$.

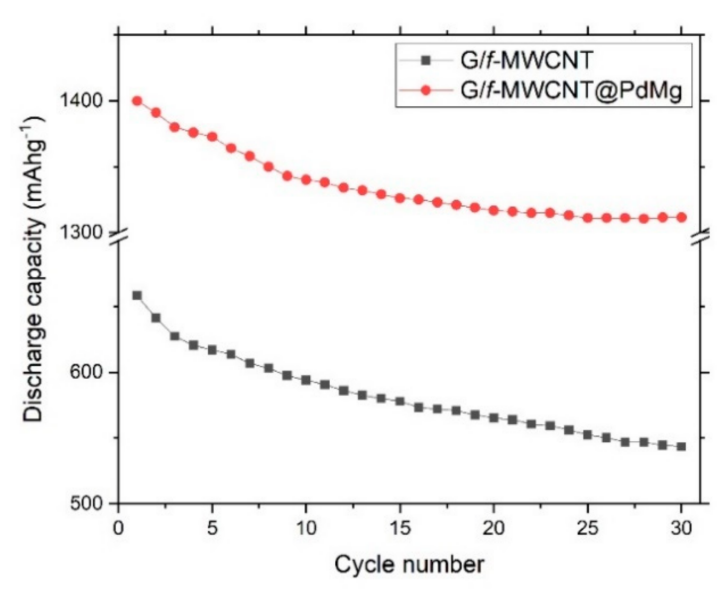

(a)

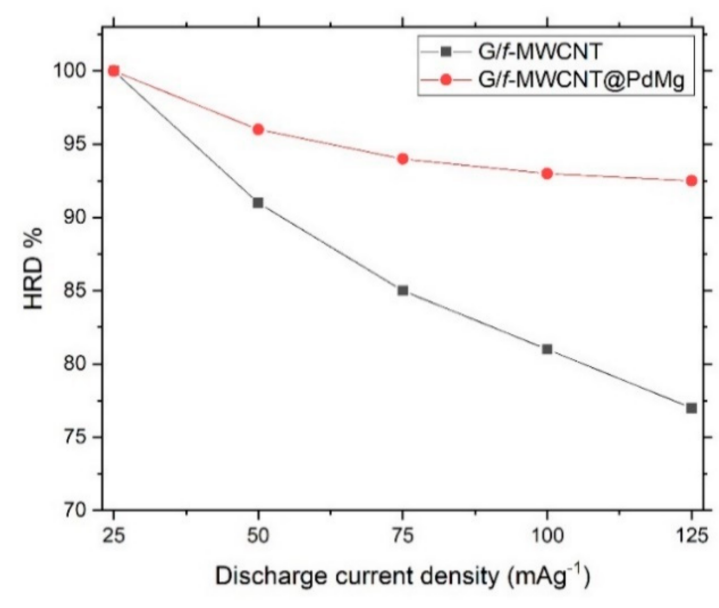

(b)

Figure 6. (a) Discharge capacities of the G/f-MWCNT and G/f-MWCNT@PdMg nanocomposites at a current density of $25 \mathrm{~mA} / \mathrm{g}$ : G/f-MWCNT electrode; (b) high-rate discharge-ability of the G/f-MWCNT and G/f-MWCNT@PdMg nanocomposites. 
The improved HRD performance of the G/f-MWCNT@PdMg sample compared to the G/f-MWCNT can be explained as follows: the small sizes of PdMg nanoparticles for the composite sample diminish the diffusion lengths for hydrogen from the absorbed/adsorbed sites to the electrode/electrolyte interface. This assists in the contact between alloy and electrolyte, and provides quick charge transfer networks within the sample.

Figure 7 shows an illustration of the hydrogen absorption process in the sample. Hydrogen is stored in materials through two different mechanisms: absorption when hydrogen molecules are stored directly within the free spaces in the material, and adsorption when hydrogen atoms bonded to the surface of the material. Generally, metal hydride is formed through a sequence of stages explained as follows: physisorption (Van der Waals attractive forces between the metal and hydrogen molecules catches in an accessible volume close to the metal) $\rightarrow$ dissociation of the hydrogen molecules at the metal surface (the metal catalyst, for example; Pd assists this process) $\rightarrow$ chemisorption, i.e., the formation of the hydrogen bond at the metal surface $\rightarrow \alpha$-phase formation (hydrogen occupies interstitial sites) $\rightarrow \beta$-phase (new physicochemical properties arise with the increasing concentration of hydrogen in the metal crystal lattice) $\rightarrow$ vanishing of $\alpha$-phase.

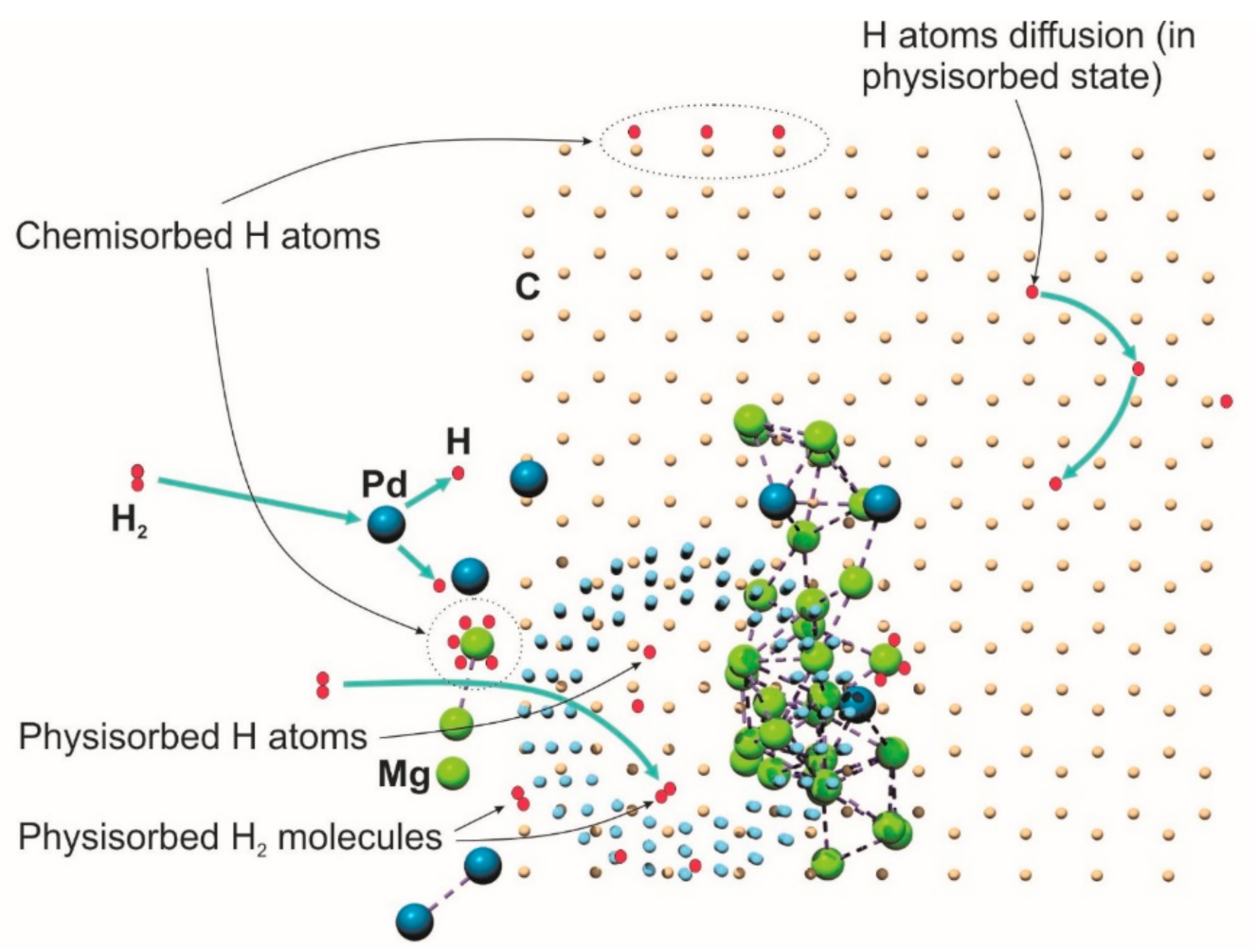

Figure 7. Schematic illustration of hydrogen absorption in G/f-MWCNT@PdMg sample.

Therefore, the nanosize of PdMg particles allows more hydrogen dissociation sites and shortened hydrogen diffusion pathways that improve storage kinetics [65-68]. In addition, a larger surface area increases the number of atoms at the grain boundaries, which in turn enhances hydrogen diffusion rates. On the other hand, the large surface area of graphene/nanotube as well as the large interstitial volumes within the nanofibrous structure create huge hydrogen storage sites. Figure $2 c$ shows the XRD pattern of the G/fMWCNT@PdMg sample after hydrogenation. The pattern exhibits two new peaks (located at $67.68^{\circ}$ and $80.2^{\circ}$ ) in comparison to the sample before hydrogenation in Figure $2 \mathrm{~b}$. These new peaks arise from tetragonal $\mathrm{MgH}_{2}$ (JCPDS card no. 00-089-7887) and fcc PdH (JCPDS card no. 00-065-0557) phases. As mentioned before, the deposited PdMg film contains two mixed phases, one of which is the host Pd phase with dopped $\mathrm{Mg}$ atoms. This phase is characterized by the high hydrogen storage capacity. Most Mg atoms are surrounded by $\mathrm{Pd}$ atoms. This arrangement allows $\mathrm{Mg}$ atoms to absorb more hydrogen, and also creates 
more hydrogen diffusion paths to graphene and nanotube structures with a high hydrogen diffusion rate. The catalytic nature of palladium enhanced the absorption kinetics, and the presence of magnesium increased the storage capacity of hydrogen. The fibrous structure of the nanotubes created room for further absorption of molecular hydrogen. The graphene layers increased the surface area for atomic hydrogen absorption. Nanoparticles made of metal alloy embossed with a carbon nanostructure appear to be a viable material for hydrogen storage applications.

\section{Conclusions}

This work investigates the hydrogen storage capacity of graphene/multiwall carbon nanotubes decorated with PdMg alloy nanoparticles (G/f-MWCNT@PdMg). It was found that the presence of PdMg nanoparticles increased the hydrogen absorption capacity by $53 \%$ compared to the sample without PdMg decorated nanoparticles. The obtained hydrogen capacities for both samples with and without PdMg nanoparticles are $2.86 \mathrm{wt} \%$ and $5.53 \mathrm{wt} \%$, respectively. This higher value of the hydrogen storage capacity was ascribed to the fact that PdMg nanoparticles act as active reaction sites for molecular and atomic hydrogen absorption and desorption. The catalytic nature of $\mathrm{Pd}$ metal enhanced the absorption kinetics, and the presence of $\mathrm{Mg}$ increased the hydrogen storage capacity.

Furthermore, the fibrous structure of the nanotubes created rooms for more molecular hydrogen absorption. Moreover, the graphene layers increased the surface area for atomic hydrogen absorption due to their catalytic nature. Thus, the carbon nanostructure decorated with PdMg alloy nanoparticles appears to be a viable material for hydrogen storage applications.

Author Contributions: Conceptualization, B.A., A.A. and E.-S.S.; methodology, B.A., N.S., A.A. and A.I.; investigation, M.A., S.A. and A.A.-O; resources, E.-S.S. and A.I.; writing-original draft preparation, B.A., E.-S.S., N.S. and A.A.-G; writing—review and editing, B.A., A.I. and E.-S.S.; project administration, A.A.-O. and E.-S.S.; funding acquisition, A.A.-G. and E.-S.S. All authors have read and agreed to the published version of the manuscript.

Funding: Deanship of Scientific Research (DSR), King Abdulaziz University (KAU), SA, grant no. (FP-77-43).

Data Availability Statement: No data.

Acknowledgments: The Deanship of Scientific Research (DSR) at King Abdulaziz University, Jeddah, Saudi Arabia has funded this project, under grant no. (FP-77-43). Some authors (A.A.-O \& E.S.) would also like to thank King Abdulaziz City for Science and Technology (KACST) for supporting the project no. 1-18-01-009-0079.

Conflicts of Interest: The authors declare no conflict of interest.

\section{References}

1. He, T.; Pachfule, P.; Wu, H.; Xu, Q.; Chen, P. Hydrogen carriers. Nat. Rev. Mater. 2016, 1, 16059. [CrossRef]

2. Van Renssen, S. The hydrogen solution? Nat. Clim. Chang. 2020, 10, 799-801. [CrossRef]

3. El-Eskandarany, M.S.; Al-Salem, S.M.; Ali, A.N.; Banyan, M.; Al-Ajmi, F.; Al-Duweesh, A. From gangue to the fuel-cells application. Sci. Rep. 2020, 10, 20022. [CrossRef] [PubMed]

4. Serra, J.M.; Borrás-Morell, J.F.; García-Baños, B.; Balaguer, M.; Plaza-González, P.; Santos-Blasco, J.; Catalán-Martínez, D.; Navarrete, L.; Catalá-Civera, J.M. Hydrogen production via microwave-induced water splitting at low temperature. Nat. Energy 2020, 5, 910-919. [CrossRef]

5. Chu, S.; Majumdasr, A. Opportunities and challenges for a sustainable energy future. Nature 2012, 488, 294-303. [CrossRef]

6. He, T.; Cao, H.; Chen, P. Complex Hydrides for Energy Storage, Conversion, and Utilization. Adv. Mater. 2019, 31, 1902757. [CrossRef] [PubMed]

7. Firlej, L.; Pfeifer, P.; Kuchta, B. Understanding Universal Adsorption Limits for Hydrogen Storage in Nano Porous Systems. Adv. Mater. 2013, 25, 5971-5974. [CrossRef]

8. Liu, C.; Li, F.; Ma, L.-P.; Cheng, H.-M. Advanced Materials for Energy Storage. Adv. Mater. 2010, 22, E28-E62. [CrossRef]

9. Hu, Y.H.; Zhang, L. Hydrogen Storage in Metal-Organic Frameworks. Adv. Mater. 2010, 22, E117-E130. [CrossRef]

10. Kato, R.; Nishide, H. Polymers for carrying and storing hydrogen. Polym. J. 2018, 50, 77-82. [CrossRef]

11. Schlapbach, L.; Züttel, A. Hydrogen-storage materials for mobile applications. Nature 2001, 414, 353-358. [CrossRef] 
12. Jin, J.; Fu, L.; Yang, H.; Ouyang, J. Carbon hybridized halloysite nanotubes for high-performance hydrogen storage capacities. Sci. Rep. 2015, 5, 12429. [CrossRef]

13. Mohtadi, R.; Orimo, S.-i. The renaissance of hydrides as energy materials. Nat. Rev. Mater. 2016, 2, 16091. [CrossRef]

14. Adametz, P.; Müller, K.; Arlt, W. Energetic evaluation of hydrogen storage in metal hydrides. Int. J. Energy Res. 2016, 40, 1820-1831. [CrossRef]

15. Tarasov, B.P.; Fursikov, P.V.; Volodin, A.A.; Bocharnikov, M.S.; Shimkus, Y.Y.; Kashin, A.M.; Yartys, V.A.; Chidziva, S.; Pasupathi, S.; Lototskyy, M.V. Metal hydride hydrogen storage and compression systems for energy storage technologies. Int. J. Hydrog. Energy 2020, 46, 13647-13657. [CrossRef]

16. Kumar, K.; Alam, M.; Verma, S.; Dutta, V. Analysis of metal hydride storage on the basis of thermophysical properties and its application in microgrid. Energy Convers. Manag. 2020, 222, 113217. [CrossRef]

17. Kojima, Y.; Yamaguchi, M. Investigation on hydrogen dissociation pressure, heat of formation and strain energy of metal hydrides. J. Alloys Compd. 2020, 840, 155686. [CrossRef]

18. Lim, K.L.; Kazemian, H.; Yaakob, Z.; Daud, W.R.W. Solid-state Materials and Methods for Hydrogen Storage: A Critical Review. Chem. Eng. Technol. 2010, 33, 213-226. [CrossRef]

19. Lin, I.H.; Tong, Y.-J.; Hsieh, H.-J.; Huang, H.-W.; Chen, H.-T. Hydrogen adsorption and storage in boron-substituted and nitrogen-substituted nano-carbon materials decorated with alkaline earth metals. Int. J. Energy Res. 2016, 40, 230-240. [CrossRef]

20. Salehabadi, A.; Umar, M.F.; Ahmad, A.; Ahmad, M.I.; Ismail, N.; Rafatullah, M. Carbon-based nanocomposites in solid-state hydrogen storage technology: An overview. Int. J. Energy Res. 2020, 44, 11044-11058. [CrossRef]

21. Mohan, M.; Sharma, V.K.; Kumar, E.A.; Gayathri, V. Hydrogen storage in carbon materials-A review. Energy Storage 2019, 1, e35. [CrossRef]

22. Wang, C.; Tang, C.; Fu, L. An effective method to screen carbon (boron, nitrogen) based two-dimensional hydrogen storage materials. Int. J. Hydrog. Energy 2020, 45, 25054-25064. [CrossRef]

23. Li, Y.; Xiao, Y.; Dong, H.; Zheng, M.; Liu, Y. Polyacrylonitrile-based highly porous carbon materials for exceptional hydrogen storage. Int. J. Hydrog. Energy 2019, 44, 23210-23215. [CrossRef]

24. Salehabadi, A.; Salavati-Niasari, M.; Ghiyasiyan-Arani, M. Self-assembly of hydrogen storage materials based multi-walled carbon nanotubes (MWCNTs) and Dy3Fe5O12 (DFO) nanoparticles. J. Alloys Compd. 2018, 745, 789-797. [CrossRef]

25. Yang, S.J.; Jung, H.; Kim, T.; Park, C.R. Recent advances in hydrogen storage technologies based on nanoporous carbon materials. Prog. Nat. Sci. Mater. Int. 2012, 22, 631-638. [CrossRef]

26. Papp, G.; Csorba, J.; Laurenczy, G.; Joó, F. A Charge/Discharge Device for Chemical Hydrogen Storage and Generation. Angew. Chem. Int. Ed. 2011, 50, 10433-10435. [CrossRef]

27. Jiang, H.-L.; Singh, S.K.; Yan, J.-M.; Zhang, X.-B.; Xu, Q. Liquid-Phase Chemical Hydrogen Storage: Catalytic Hydrogen Generation under Ambient Conditions. ChemSusChem 2010, 3, 541-549. [CrossRef]

28. Moury, R.; Demirci, U.B.; Ichikawa, T.; Filinchuk, Y.; Chiriac, R.; van der Lee, A.; Miele, P. Sodium Hydrazinidoborane: A Chemical Hydrogen-Storage Material. ChemSusChem 2013, 6, 667-673. [CrossRef]

29. Moussa, G.; Moury, R.; Demirci, U.B.; Şener, T.; Miele, P. Boron-based hydrides for chemical hydrogen storage. Int. J. Energy Res. 2013, 37, 825-842. [CrossRef]

30. Lang, C.; Jia, Y.; Yao, X. Recent advances in liquid-phase chemical hydrogen storage. Energy Storage Mater. 2020, 26, 290-312 [CrossRef]

31. Brooks, K.P.; Sprik, S.J.; Tamburello, D.A.; Thornton, M.J. Design tool for estimating chemical hydrogen storage system characteristics for light-duty fuel cell vehicles. Int. J. Hydrog. Energy 2018, 43, 8846-8858. [CrossRef]

32. Demirci, U.B. Ammonia borane, a material with exceptional properties for chemical hydrogen storage. Int. J. Hydrog. Energy 2017, 42, 9978-10013. [CrossRef]

33. Semelsberger, T.A.; Brooks, K.P. Chemical hydrogen storage material property guidelines for automotive applications. J. Power Sources 2015, 279, 593-609. [CrossRef]

34. Zhang, J.; Yao, Y.; He, L.; Zhou, X.J.; Yu, L.P.; Lu, X.Z.; Peng, P. Hydrogen storage properties and mechanisms of as-cast, homogenized and ECAP processed Mg98.5Y1Zn0.5 alloys containing LPSO phase. Energy 2020, 217, 119315. [CrossRef]

35. Baroutaji, A.; Arjunan, A.; Ramadan, M.; Alaswad, A.; Achour, H.; Abdelkareem, M.A.; Olabi, A.-G. Nanocrystalline Mg2Ni for Hydrogen Storage. In Reference Module in Materials Science and Materials Engineering; Elsevier: Amsterdam, The Netherlands, 2021.

36. Pandey, A.P.; Bhatnagar, A.; Shukla, V.; Soni, P.K.; Singh, S.; Verma, S.K.; Shaneeth, M.; Sekkar, V.; Srivastava, O.N. Hydrogen storage properties of carbon aerogel synthesized by ambient pressure drying using new catalyst triethylamine. Int. J. Hydrog. Energy 2020, 45, 30818-30827. [CrossRef]

37. Tan, K.C.; Yu, Y.; Chen, R.; He, T.; Jing, Z.; Pei, Q.; Wang, J.; Chua, Y.S.; Wu, A.; Zhou, W.; et al. Metallo-N-Heterocycles-A new family of hydrogen storage material. Energy Storage Mater. 2020, 26, 198-202. [CrossRef]

38. Jain, V.; Kandasubramanian, B. Functionalized graphene materials for hydrogen storage. J. Mater. Sci. 2020, 55, 1865-1903. [CrossRef]

39. Song, L.-F.; Jiang, C.-H.; Liu, S.-S.; Jiao, C.-L.; Si, X.-L.; Wang, S.; Li, F.; Zhang, J.; Sun, L.-X.; Xu, F.; et al. Progress in improving thermodynamics and kinetics of new hydrogen storage materials. Front. Phys. 2011, 6, 151-161. [CrossRef] 
40. Coppola, C.M.; Tolbatov, I.; Tranca, I.C.; Coletti, C.; Marrone, A.; Storchi, L.; Profio, P.D.; Re, N.; Kazandjian, M.V.; Pellecchia, A.; et al. A database approach for materials selection for hydrogen storage in aerospace technology. Rend. Lincei. Sci. Fis. E Nat. 2019, 30, 287-296. [CrossRef]

41. Wang, J.; Li, H.-W.; Chen, P. Amides and borohydrides for high-capacity solid-state hydrogen storage-materials design and kinetic improvements. MRS Bull. 2013, 38, 480-487. [CrossRef]

42. Ding, Z.; Wu, P.; Shaw, L. Solid-state hydrogen desorption of $2 \mathrm{MgH}_{2}+\mathrm{LiBH} 4$ nano-mixture: A kinetics mechanism study. J. Alloys Compd. 2019, 806, 350-360. [CrossRef]

43. Ouyang, L.; Chen, K.; Jiang, J.; Yang, X.-S.; Zhu, M. Hydrogen storage in light-metal based systems: A review. J. Alloys Compd. 2020, 829, 154597. [CrossRef]

44. Zhu, M.; Lu, Y.; Ouyang, L.; Wang, H. Thermodynamic Tuning of Mg-Based Hydrogen Storage Alloys: A Review. Materials 2013, 6, 4654-4674. [CrossRef]

45. Oliva, D.G.; Fuentes, M.; Borzone, E.M.; Meyer, G.O.; Aguirre, P.A. Hydrogen storage on LaNi ${ }_{5}-x S_{n}$. Experimental and phenomenological Model-based analysis. Energy Convers. Manag. 2018, 173, 113-122. [CrossRef]

46. Konik, P.; Berdonosova, E.; Savvotin, I.; Zadorozhnyy, V.; Zadorozhnyy, M.; Semenov, D.; Korol, A.; Kvaratskheliya, A.; Klyamkin, S. Structure and hydrogenation features of mechanically activated LaNi 5 -type alloys. Int. J. Hydrog. Energy 2020, 46, 13638-13646. [CrossRef]

47. Orgaz, E.; Gupta, M. Electronic structure of BaReH9. J. Alloys Compd. 1999, 293-295, 217-221. [CrossRef]

48. Ianni, E.; Sofianos, M.V.; Rowles, M.R.; Sheppard, D.A.; Humphries, T.D.; Buckley, C.E. Synthesis of $\mathrm{NaAlH}_{4} / \mathrm{Al}_{\mathrm{l}}$ composites and their applications in hydrogen storage. Int. J. Hydrog. Energy 2018, 43, 17309-17317. [CrossRef]

49. Ding, Z.; Li, S.; Zhou, Y.; Chen, Z.; Yang, W.; Ma, W.; Shaw, L. LiBH4 for hydrogen storage-New perspectives. Nano Mater. Sci. 2020, 2, 109-119. [CrossRef]

50. Ding, Z.; Li, H.; Shaw, L. New insights into the solid-state hydrogen storage of nanostructured $\mathrm{LiBH}_{4}-\mathrm{MgH}_{2} \mathrm{system}$ Chem. Eng. J. 2020, 385, 123856. [CrossRef]

51. Ding, Z.; Shaw, L. Enhancement of Hydrogen Desorption from Nanocomposite Prepared by Ball Milling $\mathrm{MgH}_{2}$ with In Situ Aerosol Spraying $\mathrm{LiBH}_{4}$. ACS Sustain. Chem. Eng. 2019, 7, 15064-15072. [CrossRef]

52. Ding, Z.; Lu, Y.; Li, L.; Shaw, L. High reversible capacity hydrogen storage through Nano-LiBH $4+\mathrm{Nano}_{4} \mathrm{MgH}_{2}$ system. Energy Storage Mater. 2019, 20, 24-35. [CrossRef]

53. Ding, Z.; Zhao, X.; Shaw, L.L. Reaction between $\mathrm{LiBH}_{4}$ and $\mathrm{MgH}_{2}$ induced by high-energy ball milling. J. Power Sources 2015, 293, 236-245. [CrossRef]

54. Petrushenko, I.K.; Petrushenko, K.B. Hydrogen adsorption on graphene, hexagonal boron nitride, and graphene-like boron nitride-carbon heterostructures: A comparative theoretical study. Int. J. Hydrog. Energy 2018, 43, 801-808. [CrossRef]

55. Shalaan, E.; Inoue, A.; Al-Marzouki, F.; Al-Heniti, S.; Obaid, A.Y.; Al-Hashimi, S. Formation of nano-porous Pd(Ni) structure produced by dealloying Zr-Al-Ni-Pd base glassy alloys and their electrochemical properties. J. Non-Cryst. Solids 2019, 518, 123-127. [CrossRef]

56. $\mathrm{Wu}, \mathrm{X} . ; \mathrm{He}, \mathrm{G} . ;$ Ding, Y. Dealloyed nanoporous materials for rechargeable lithium batteries. Electrochem. Energy Rev. 2020, 3 , 541-580. [CrossRef]

57. Zhou, X.; Zhao, H.; Fu, Z.; Qu, J.; Zhong, M.; Yang, X.; Yi, Y.; Wang, C. Nanoporous Ni with High Surface Area for Potential Hydrogen Storage Application. Nanomaterials 2018, 8, 394. [CrossRef]

58. Baburin, I.A.; Klechikov, A.; Mercier, G.; Talyzin, A.; Seifert, G. Hydrogen adsorption by perforated graphene. Int. J. Hydrog. Energy 2015, 40, 6594-6599. [CrossRef]

59. Nagar, R.; Vinayan, B.P.; Samantaray, S.S.; Ramaprabhu, S. Recent advances in hydrogen storage using catalytically and chemically modified graphene nanocomposites. J. Mater. Chem. A 2017, 5, 22897-22912. [CrossRef]

60. Rangel, E.; Sansores, E. Theoretical study of hydrogen adsorption on nitrogen doped graphene decorated with palladium clusters. Int. J. Hydrog. Energy 2014, 39, 6558-6566. [CrossRef]

61. Tsujimoto, M.; Tanimura, M.; Tachibana, M. Temperature dependence of the Raman spectra of multilayer graphene nanoribbons fabricated by unzipping method. Diam. Relat. Mater. 2020, 109, 108047. [CrossRef]

62. Cao, A.; Zhu, H.; Zhang, X.; Li, X.; Ruan, D.; Xu, C.; Wei, B.; Liang, J.; Wu, D. Hydrogen storage of dense-aligned carbon nanotubes. Chem. Phys. Lett. 2001, 342, 510-514. [CrossRef]

63. DiLeo, R.A.; Castiglia, A.; Ganter, M.J.; Rogers, R.E.; Cress, C.D.; Raffaelle, R.P.; Landi, B.J. Enhanced Capacity and Rate Capability of Carbon Nanotube Based Anodes with Titanium Contacts for Lithium Ion Batteries. ACS Nano 2010, 4, 6121-6131. [CrossRef] [PubMed]

64. Carter, R.; Oakes, L.; Cohn, A.P.; Holzgrafe, J.; Zarick, H.F.; Chatterjee, S.; Bardhan, R.; Pint, C.L. Solution Assembled SingleWalled Carbon Nanotube Foams: Superior Performance in Supercapacitors, Lithium-Ion, and Lithium-Air Batteries. J. Phys. Chem. C 2014, 118, 20137-20151. [CrossRef]

65. Kumara, L.S.R.; Sakata, O.; Kobayashi, H.; Song, C.; Kohara, S.; Ina, T.; Yoshimoto, T.; Yoshioka, S.; Matsumura, S.; Kitagawa, H. Hydrogen storage and stability properties of $\mathrm{Pd}-\mathrm{Pt}$ solid-solution nanoparticles revealed via atomic and electronic structure. Sci. Rep. 2017, 7, 14606. [CrossRef] [PubMed]

66. Zhou, C.; Szpunar, J.A. Hydrogen Storage Performance in Pd/Graphene Nanocomposites. ACS Appl. Mater. Interfaces 2016, 8 , 25933-25940. [CrossRef] [PubMed] 
67. Kobayashi, H.; Yamauchi, M.; Ikeda, R.; Yamamoto, T.; Matsumura, S.; Kitagawa, H. Double enhancement of hydrogen storage capacity of Pd nanoparticles by 20 at\% replacement with Ir; systematic control of hydrogen storage in Pd-M nanoparticles (M = Ir, Pt, Au). Chem. Sci. 2018, 9, 5536-5540. [CrossRef] [PubMed]

68. Adams, B.D.; Chen, A. The role of palladium in a hydrogen economy. Mater. Today 2011, 14, 282-289. [CrossRef] 